\title{
Visualizing the splicing of single pre-mRNA molecules in whole cell extract
}

\author{
DANIEL J. CRAWFORD, ${ }^{1,2,3,4}$ AARON A. HOSKINS, ${ }^{1,3,4}$ LARRY J. FRIEDMAN, ${ }^{2}$ JEFF GELLES, ${ }^{2}$ \\ and MELISSA J. MOORE ${ }^{1,4}$ \\ ${ }^{1}$ Howard Hughes Medical Institute, Brandeis University, Waltham, Massachusetts 02453, USA \\ ${ }^{2}$ Department of Biochemistry, Brandeis University, Waltham, Massachusetts 02453, USA
}

\begin{abstract}
The excision of introns from nascent eukaryotic transcripts is catalyzed by the spliceosome, a highly complex and dynamic macromolecular machine composed of RNA and protein. Because of its complexity, biochemical analysis of the spliceosome has been previously limited to bulk assays in largely unfractionated cell extracts. We now report development of methodologies for studying the splicing of isolated single pre-mRNA molecules in real time. In this system, a fluorescently tagged pre-mRNA is tethered to a glass surface via its 3 ' -end. Splicing can be observed in Saccharomyces cerevisiae whole cell extract by monitoring loss of intron-specific fluorescence with a multi-wavelength total internal reflection fluorescence (TIRF) microscope. To prolong fluorophore lifetime, two enzyme-based $\mathrm{O}_{2}$ scavenging systems compatible with splicing were also developed. This work provides a powerful new approach for elucidating the mechanisms of spliceosome function and demonstrates the feasibility of utilizing TIRF microscopy for biochemical studies of single molecules in highly complex environments.
\end{abstract}

Keywords: RNA splicing; single molecule fluorescence; spliceosome; yeast

\section{INTRODUCTION}

Within eukaryotic cells, genetic information is copied, modified, and translated by numerous macromolecular machines, each composed of dozens or even hundreds of component parts. Lack of suitable prokaryotic counterparts, limited high-resolution structural information, and an inability to reconstitute the activity in vitro from purified constituents can hinder mechanistic analysis of such machines. Moreover, biochemical studies of these systems are often limited to cell extracts-profoundly heterogeneous mixtures in which the species of interest are usually minor components and may be subject to destruction by nucleases or proteases. Furthermore, the machines

\footnotetext{
${ }^{3}$ These authors contributed equally to this work.

${ }^{4}$ Present address: Department of Biochemistry and Molecular Pharmacology, Howard Hughes Medical Institute, University of Massachusetts Medical School, Worcester, MA 01655, USA.

Reprint requests to: Jeff Gelles, Department of Biochemistry, Brandeis University, Waltham, MA 02453, USA; e-mail: Gelles@brandeis.edu; fax: (781) 736-2349; or Melissa J. Moore, Department of Biochemistry and Molecular Pharmacology, Howard Hughes Medical Institute, University of Massachusetts Medical School, Worcester, MA 01655, USA; e-mail: Melissa.Moore@umassmed.edu; fax: (508) 856-1002.

Article published online ahead of print. Article and publication date are at http://www.rnajournal.org/cgi/doi/10.1261/rna.794808.
}

themselves may have heterogeneous components and complex, branched reaction pathways that obfuscate interpretation of bulk biochemical assays and limit the availability of detailed kinetic information. To overcome these barriers, we now report single-molecule methods to analyze in cellular extract the mechanism of one of the cell's most complicated macromolecular machines, the spliceosome (Nilsen 2003).

The spliceosome is the highly dynamic catalyst responsible for removing introns from newly made precursors to mRNAs (pre-mRNAs) in the nucleus. It employs five small nuclear RNAs (snRNAs) and >100 polypeptides (Staley and Guthrie 1998; Burge et al. 1999; Jurica and Moore 2003). These components assemble on pre-mRNA to carry out two transesterification reactions (Burge et al. 1999). In the first, the $2^{\prime}-\mathrm{OH}$ of the branch point adenosine attacks the $5^{\prime}$-splice site to create a lariat and free the $5^{\prime}$-exon. In the second, the $3^{\prime}-\mathrm{OH}$ of the $5^{\prime}$-exon attacks the $3^{\prime}$-splice site to join the exons and release the intron lariat. While the overall reaction is isoenergetic, requiring no phosphoryl transfer to the pre-mRNA, the spliceosome consumes both ATP (Staley and Guthrie 1998) and GTP (Brenner and Guthrie 2006; Small et al. 2006) to power conformational rearrangements essential for assembly, catalysis, and disassembly. 
For analysis of the spliceosome and other complex systems, single-molecule fluorescence (SMF) microscopy has several advantages over bulk assays (Kelley et al. 2001; Zhuang 2005; Cornish and Ha 2007). First, the kinetic heterogeneity inherent in such systems can be readily detected, and molecules grouped according to similar patterns of behavior (Kelley et al. 2001). SMF can potentially yield a cleaner analysis of the mechanism of splicing by segregating molecules capable of carrying out the chemical steps of splicing away from chemically incompetent species during data analysis. The analogous ability to parse out structural heterogeneity has already proven invaluable for obtaining low-resolution spliceosome structures by cryoelectron microscopy (Stark and Luhrmann 2006; Ohi et al. 2007). Second, by employing various fluorophore labeling schemes and fluorescence resonance energy transfer (FRET) methods (Ha 2001), it should be possible to observe discrete steps in spliceosome assembly and catalysis and provide new structural information. Finally, the small sample size $(\sim 10 \mu \mathrm{L})$, low material requirements $(1-10$ fmol), and high sensitivity of SMF are all amenable to splicing assays. Here we describe methods that allow us to directly observe pre-mRNA splicing in real time by SMF. These experiments lay the foundation for a new approach toward obtaining detailed mechanistic insight into the mechanics and dynamics of pre-mRNA splicing in the highly complex environment of whole cell extract.

\section{RESULTS}

\section{Single-molecule fluorescence in cell extracts}

Biochemical studies of splicing have largely been conducted in two systems in vitro: HeLa nuclear extract and Saccharomyces cerevisiae whole cell extract (yeast extract [YE]). For development of a single-molecule assay, we chose the latter because of its potential for genetic manipulation. The substantial autofluorescence of cell extracts (Billinton and Knight 2001) necessitates the use of fluorophores with high quantum yields such as rhodamines, Cy dyes (Ha 2001; Rasnik et al. 2006), and Alexa dyes. The fluorophores must also be highly photostable (i.e., not photobleach) over the course of the experiment, which in the case of in vitro splicing may take upward of an hour. While some degree of photobleaching is inevitable, stability can be greatly improved by removing $\mathrm{O}_{2}$ to prevent damage by photogenerated reactive oxygen species (Rasnik et al. 2006). Enzymatic scavenging is a convenient method to deplete $\mathrm{O}_{2}$ from microliter-scale biochemical reactions; the most common method uses glucose oxidase (Fig. 1a); Benesch

a
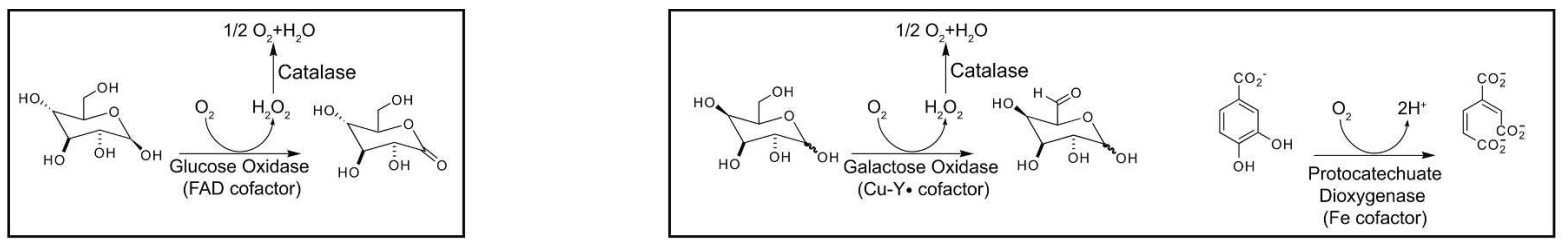

b

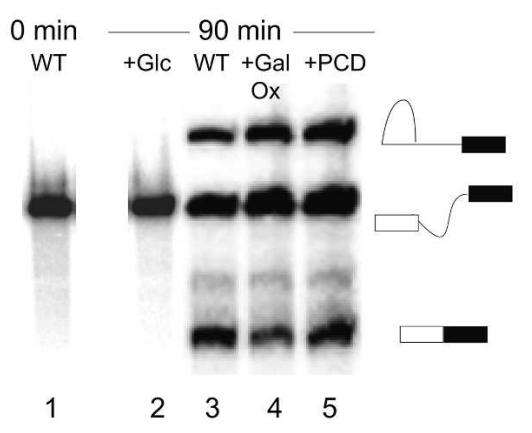

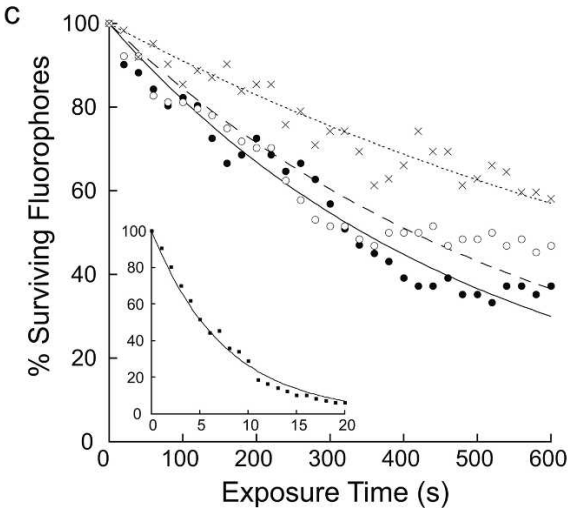

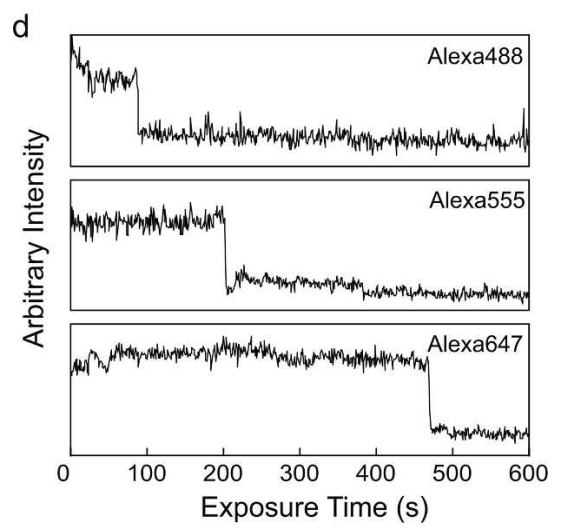

FIGURE 1. Alternative $\mathrm{O}_{2}$ scavenging systems for SMF in cell extracts. (a) $\mathrm{O}_{2}$ scavenging systems employing glucose oxidase, galactose oxidase, and protocatechuate dioxygenase (PCD). (b) Pre-mRNA splicing is inhibited by glucose but not by the galactose oxidase or PCD scavenging systems. (Lane 1) Reaction time $t=0 \mathrm{~min}$; (lane 2) $t=90 \mathrm{~min}$ after pre-incubation with $20 \mathrm{mM}$ glucose for $5 \mathrm{~min}$; (lanes 3-5) $t=90 \mathrm{~min}$ for a control splicing reaction (lane 3) or in the presence of galactose oxidase (lane 4) or PCD (lane 5) $\mathrm{O}_{2}$ scavenging systems, each with 2 mM trolox (Rasnik et al. 2006). (From top to bottom) Cartoons represent lariat intermediate, pre-mRNA, and mRNA; (lines) the intron; (boxes) exons. (c) Normalized photobleaching curves for single molecules $(N=100-200)$ of Alexa647-labeled oligo 1 supplemented with $2 \mathrm{mM}$ trolox in YE in the absence of $\mathrm{O}_{2}$ scavenger (inset) or in the presence of glucose oxidase $(\bullet$, solid line), galactose oxidase $(\bigcirc$, dashed line), or PCD scavenging system ( $\times$, dotted line). (d) Representative relative fluorescence intensity time courses tracking single molecules of dye-labeled oligo 1 in YE with the PCD $\mathrm{O}_{2}$ scavenging system. Under continuous illumination, fluorescence persists for tens or hundreds of seconds then abruptly drops when the dye photobleaches. 
and Benesch 1953), which requires a high glucose concentration $(\sim 20 \mathrm{mM})$ for efficient $\mathrm{O}_{2}$ removal (Benesch and Benesch 1953; Yildiz et al. 2003). However, YE contains endogenous hexo- and glucokinase activities; therefore, addition of $20 \mathrm{mM}$ glucose to splicing reactions rapidly depletes ATP and consequently inhibits splicing (Fig. 1b); Tatei et al. 1989; Liao et al. 1992).

We tested two possible alternative $\mathrm{O}_{2}$ scavenging systems that employ either galactose oxidase (Whittaker 2002) or protocatechuate dioxygenase (PCD) (Fig. 1a; Patil and Ballou 2000). Bulk assays indicated that addition of Pichia pastoris galactose oxidase (Whittaker and Whittaker 2000), bovine liver catalase, Pseudomonas PCD, Burkholderia cepacia PCD (Patil and Ballou 2000), $30 \mathrm{mM}$ galactose, and/or $5 \mathrm{mM}$ protocatechuate had no inhibitory effects on splicing of the well-characterized RP51A pre-mRNA transcript (Fig. 1b; Rymond and Rosbash 1985; data not shown). To test the efficacy of galactose oxidase and PCD for $\mathrm{O}_{2}$ scavenging under SMF conditions, we used a fluorescently labeled, biotinylated 2'-O-Me oligonucleotide (oligo 1). The oligo was attached to a polyethylene glycol (PEG)/biotin-derivatized glass surface via streptavidin (Rasnik et al. 2004; Friedman et al. 2006), and single oligo molecules were visualized with a multiwavelength total internal reflection fluorescence (TIRF) microscope (Friedman et al. 2006). Under splicing conditions in the absence of $\mathrm{O}_{2}$ scavenger, Alexa647 fluorophores excited at $633 \mathrm{~nm}$ photobleached almost completely within $20 \mathrm{sec}$ (Fig. 1c, inset). In contrast, both the P. pastoris galactose oxidase and B. cepacia PCD systems extended fluorophore lifetimes $>100$-fold, performing comparably to the glucose oxidase system (Fig. 1c). In all cases, enhanced photostability was observed within 5 min and continued for $>90$ min (data not shown), a timescale relevant for in vitro splicing reactions.

To generalize the observations made with Alexa647, we studied the single-molecule signal-to-noise ratio $(\mathrm{S} / \mathrm{N})$ and photostability (i.e., fluorophore lifetime) for several common fluorescent dyes attached to oligo 1 in either buffer or YE containing B. cepacia PCD (Fig. 1d; Table 1). In all cases, high $\mathrm{S} / \mathrm{N}$ and long lifetimes were observed, indicating that the PCD system is useful with a variety of fluorophores. The presence of YE modestly reduced photostabil- ity (approximately two- to threefold) and, for Alexa488 and Alexa647, caused a small $(\sim 25 \%)$ drop in the observed $\mathrm{S} / \mathrm{N}$. Nonetheless, SMF from all dyes tested was readily observable in YE for extended periods of time (Fig. 1d).

Taken together, our results indicate that (1) the autofluorescence of YE is not an insurmountable problem for SMF experiments using TIRF microscopy; and (2) galactose oxidase and PCD are useful alternatives to glucose oxidase in such studies. In the studies reported below, B. cepacia PCD was used exclusively.

\section{Monitoring splicing with an intron-complementary oligo}

In all of the studies reported here, we used two-color SMF colocalization to detect pre-mRNA splicing. In brief, singleintron pre-mRNA molecules were tagged with a fluorescent dye of one color in the intron and a dye of another color in an exon. Splicing was detected as the conversion of a single molecule displaying both colors of fluorescence to a molecule displaying exon fluorescence only.

As one approach for labeling the intron, we employed a complementary fluorescent oligo (Fig. 2a). A 3'-biotinylated, RP51A pre-mRNA covalently tagged with Alexa647 in the $3^{\prime}$-exon was attached to a PEG-biotin-derivatized glass surface via streptavidin (Rasnik et al. 2004; Friedman et al. 2006). A single fluorescent oligo was then hybridized to the intron. When the pre-mRNA is spliced, the intronassociated oligo should depart the surface; since TIRF detects only fluorophores near the surface, this results in loss of the intron fluorescence signal.

Fluorophore (Alexa555 versus Alexa647), oligo length (12-19 nucleotides [nt]), oligo target sequence, and fluorophore attachment position ( $5^{\prime}$ or $\left.3^{\prime}\right)$ were all varied to optimize specificity and reduce oligo dissociation rates (data not shown). The best results were obtained with a hybrid 2'-O-Me/locked nucleic acid (LNA) oligo (Table 2, oligo 2) to which Alexa555 was attached at the $5^{\prime}$-end. Oligo 2 binds the intron $24 \mathrm{nt}$ downstream from the $5^{\prime}$-splice site and $36 \mathrm{nt}$ upstream of the UACUAAC branch point sequence, a region not expected to be important for splicing. Native gel analysis confirmed that oligo 2 could

TABLE 1. Properties of several common fluorescent dyes in both buffer and cell extract

\begin{tabular}{|c|c|c|c|c|c|c|c|c|}
\hline \multirow[b]{2}{*}{ Fluorophore } & \multirow[b]{2}{*}{$\begin{array}{c}\text { Excitation } \\
\lambda(\mathrm{nm})\end{array}$} & \multirow[b]{2}{*}{$\begin{array}{l}\text { Laser power } \\
\qquad(\mu \mathrm{W})^{\mathrm{a}}\end{array}$} & \multicolumn{3}{|c|}{ Buffer } & \multicolumn{3}{|c|}{ Yeast extract } \\
\hline & & & $\begin{array}{c}\text { Survival } \\
\text { lifetime (sec) }\end{array}$ & $S / N$ & $\begin{array}{c}\text { Photon } \\
\text { count }\left(\times 10^{5}\right)^{\mathrm{b}}\end{array}$ & $\begin{array}{c}\text { Survival } \\
\text { lifetime (sec) }\end{array}$ & $\mathrm{S} / \mathrm{N}$ & $\begin{array}{c}\text { Photon } \\
\text { count }\left(\times 10^{5}\right)^{\mathrm{b}}\end{array}$ \\
\hline Alexa488 & 488 & 226 & $1156 \pm 6$ & $10.6 \pm 2.0$ & $10.6 \pm 0.2$ & $326 \pm 2$ & $7.8 \pm 1.3$ & $3.5 \pm 0.6$ \\
\hline Cy3 & 532 & 110 & $1384 \pm 8$ & $15.6 \pm 2.0$ & $16.9 \pm 0.3$ & $628 \pm 4$ & $16.1 \pm 2.5$ & $10.7 \pm 0.2$ \\
\hline Alexa555 & 532 & 110 & $820 \pm 21$ & $13.9 \pm 2.7$ & $5.8 \pm 0.8$ & $508 \pm 5$ & $13.5 \pm 4.0$ & $7.3 \pm 1.0$ \\
\hline Alexa647 & 633 & 140 & $3580 \pm 29$ & $22.9 \pm 5.9$ & $74.3 \pm 3.0$ & $1066 \pm 34$ & $15.6 \pm 2.9$ & $22.5 \pm 4.1$ \\
\hline
\end{tabular}


a

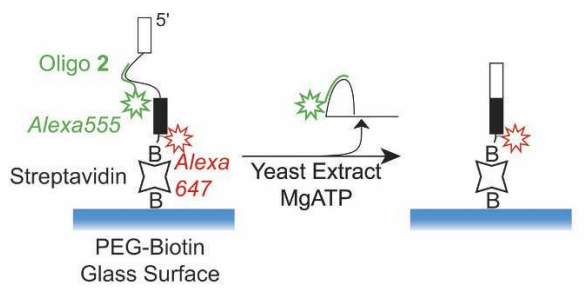

b

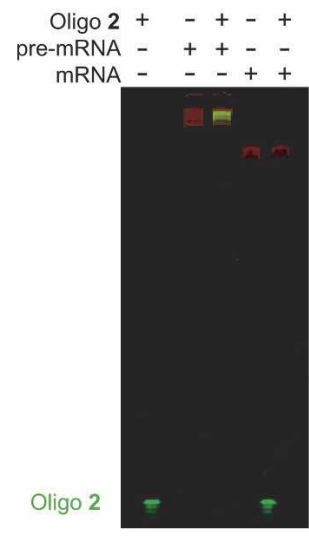

d

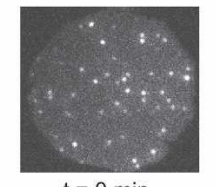

$\mathrm{t}=0 \mathrm{~min}$

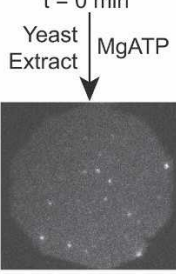

$\mathrm{t}=90 \mathrm{~min}$

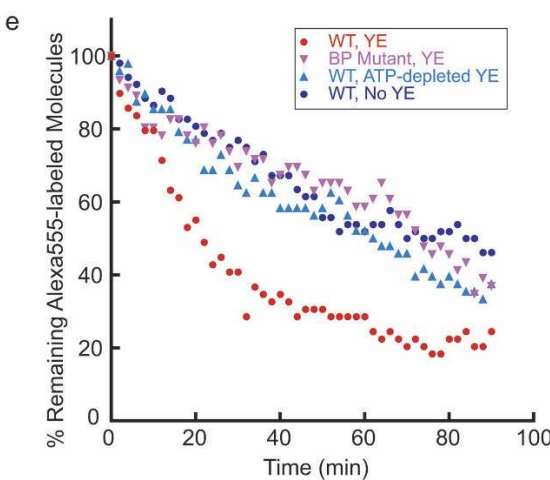

FIGURE 2. SMF detection of pre-mRNA splicing with an introncomplementary oligo. (a) Strategy for observing splicing using a fluorescent LNA/2'-O Me oligo (oligo 2) complementary to the intron; (B) biotin. (b) Composite two-color fluorescence image of a native polyacrylamide gel showing that oligo 2 (green) binds to premRNA but not mRNA (both red). (c) Oligo 2 does not inhibit premRNA splicing. Splicing reactions (lanes 1,2) without or (lane 3) with a fivefold excess of oligo 2 were analyzed by denaturing PAGE. $(d)$ TIRF microscope fields showing fluorescence of single oligo 2 molecules annealed to surface-immobilized pre-mRNAs before and after splicing. (e) Remaining oligo 2 fluorescence in TIRF experiments under splicing conditions (WT pre-mRNA) or in non-splicing controls using either a branch point mutant (BP Mutant), ATPdepleted YE, or without YE.

discriminate between pre-mRNA and mRNA (Fig. 2b), and bulk assays showed that it did not alter significantly splicing rates or efficiency (Fig. 2c).

When the labeled pre-mRNA was immobilized on the surface and monitored by TIRF microscopy, we observed isolated spots of colocalized Alexa555 (Fig. 2d) and Alexa647 fluorescence (data not shown). Alexa555 fluores- cence in a single microscope field was monitored under splicing conditions (YE + ATP) for 90 min. To limit photobleaching during splicing reactions, a single frame (1 sec exposure) was acquired intermittently such that cumulative photobleaching was $\leq 10 \%$. When observed in this way, most $(60 \%-70 \%)$ of the Alexa555 fluorescence was lost within $40 \mathrm{~min}$ (Fig. 2e). In contrast, with a pre-mRNA containing an $\mathrm{A} \rightarrow \mathrm{C}$ branch point mutation, which prevents splicing (Newman et al. 1985; data not shown), only $30 \%$ of the signal was lost over the same time. Similar results were obtained with wild-type pre-mRNA in other control experiments that either lacked YE or used ATP-depleted YE (Fig. 2e). The signal loss in control experiments was probably due to oligo dissociation from the pre-mRNA since photobleaching under this limited exposure regimen is minimal. Taken together, these results indicate that a significant portion ( $\sim 30 \%$ of the original oligo-bound intron) of oligo 2 fluorescence loss from the wild type substrate under splicing conditions was due to either intron release via splicing or oligo dissociation via spliceosome- and ATPdependent substrate remodeling.

\section{Monitoring splicing with fluorescent pre-mRNA}

As an alternate approach for monitoring single-molecule splicing, we directly incorporated the intron fluorescent label into the pre-mRNA. Using standard RNA ligation methodologies, we prepared wild-type and $\mathrm{A} \rightarrow \mathrm{C}$ branch point mutant RP51A pre-mRNA substrates each containing two covalently attached fluorophores: $\mathrm{Cy} 3$ located in the $5^{\prime}$-exon $7 \mathrm{nt}$ upstream of the $5^{\prime}$-splice site and Alexa647 located in the intron $10 \mathrm{nt}$ downstream from the $5^{\prime}$-splice site (Fig. 3a). Both RNAs also contained a biotin attached to the $3^{\prime}$-end as above. In bulk splicing assays, the wild-type Cy3:Alexa647:biotin pre-mRNA was spliced with a similar rate and efficiency $(25 \%-30 \%)$ as the corresponding unmodified transcript (Fig. 3b,c; data not shown). As expected, the branch point mutant pre-mRNA exhibited no splicing under these conditions (Fig. 3b).

This design had multiple advantages for SMF. First, it eliminated the dissociation problem inherent to the complementary oligo approach. Second, it enabled us to eliminate from our single-molecule analyses any loss in fluorescence due to hydrolysis or nuclease activity. When attached to a surface via the $3^{\prime}$-biotin, the $5^{\prime}$-exon Cy3 is distal to the surface relative to the intronic Alexa647 (Fig. 4a). Therefore if data analysis is restricted to only those molecules still retaining $5^{\prime}$-exon fluorescence at the end of the experiment, loss of intron fluorescence must reflect either photobleaching or intron dissociation via splicing (Fig. 4a). Because the branch point mutant cannot splice, analysis of its behavior measures the photobleaching rate.

To detect splicing at the single-molecule level, wild-type and mutant pre-mRNAs were tethered to a PEG-biotinderivatized glass surface, and then individual fields of 
Crawford et al.

TABLE 2. Oligos

\begin{tabular}{lll}
\hline Name & \multicolumn{1}{c}{ Sequence } & Source \\
\hline Oligo $\mathbf{1}$ & mAmUmCmCmGmGmAmGmCmGmAmG(5-N-U)mAmGmA-Biotin & Dharmacon \\
Oligo $\mathbf{2}$ & $\mathrm{NH}_{2}-\mathrm{T}+\mathrm{G}+\mathrm{T}+\mathrm{CmCmUmUmAmA+A+A+G+C}$ & IDT \\
Oligo $\mathbf{3}$ & CTCGCTCCGGCTTTTGGATTCTCTTCATC (DNA) & IDT \\
Oligo $\mathbf{4}$ & GCAAUAA(5-C-Cy3)AAAAUGGUAUGUUAA(5-N-U)AUGGAC (RNA) & Dharmacon \\
Oligo $\mathbf{5}$ & CCTTAAAACCTCCGTCCATATTAACATACCATTTGTATTGCGTCTCGAGATCCC (DNA) & IDT \\
Oligo $\mathbf{6}$ & 7-m-GpppGGGAAAGCUAGCUUGGGAUCUCGAGAC (RNA) & Transcript \\
Oligo $\mathbf{7}$ & mUmAmUmUmGmCmUmAdGdTdCdTmCmGmAmGmAmUmCmC & IDT \\
Oligo $\mathbf{8}$ & GGAGGCUUUUAAGGACACGUA..AUGAAGAGAAUCCAAAAGGGUCG (RNA) & Transcript \\
Oligo $\mathbf{9}$ & mCmUmCmCmGmGmAmUdCdGdAdCmCmCmUmUmUmUmGmG & IDT \\
\hline
\end{tabular}

(d) 2'-Deoxynucleotides; (m) 2'-O-methyl ribonucleotides; (+) locked nucleic acid (LNA) linkages; (5-N-U) 5-aminoallyluridine modification.

fluorophores were monitored under splicing conditions (YE + ATP) using dual-wavelength TIRF microscopy. Alexa647 fluorescence was monitored at regular intervals throughout the experiment ( $1 \mathrm{sec}$ exposure at $633 \mathrm{~nm}$ every $2 \mathrm{~min}$ ) (e.g., Fig. 4b-d,f-h), whereas Cy3 (excited at $532 \mathrm{~nm}$ for 3 sec) was imaged only at end of the assay (Fig. 4e,i). This protocol eliminated any Alexa647 photodamage by the 532-nm laser during the splicing reaction.

To evaluate splicing efficiency, we selected only those molecules exhibiting both intron fluorescence at the initial time point and 5'-exon fluorescence at the conclusion of the experiment. Time to loss of intron fluorescence was then determined for each molecule. In all cases, intron fluorescence loss occurred in a single step, indicating that the observed fluorescent spots represented single molecules (Fig. $4 j$ ). For the wild-type pre-mRNA, 32\% of molecules lost intron fluorescence over the first $60 \mathrm{~min}$ (Fig. 4b,c,k), as compared to only $7 \%$ for the branch point mutant control (Fig. 4f,g,k). Thus, $\sim 25 \%$ of intact wild-type pre-mRNA molecules were processed by the spliceosome through the point of intron release during the first $60 \mathrm{~min}$. This splicing efficiency is comparable to what was observed in bulk splicing assays for this same substrate $(\sim 20 \%)$ (Fig. 3b; data not shown). Furthermore, from 60 min forward, intron fluorescence loss was similar between the wild-type and mutant control (Fig. 4c,d,g,h,k), indicating that splicing is essentially complete by $60 \mathrm{~min}$. Again, this timeframe is comparable to what is observed in bulk splicing assays (data not shown). Finally, the majority of individual splicing events occurred between 20 and $45 \mathrm{~min}$ (Fig. 4k), consistent with bulk spliceosome assembly rates in YE (Ruby and Abelson 1988).

\section{DISCUSSION}

We here describe methods that reliably detect splicing of single pre-mRNA molecules using two different fluorescent labeling strategies. Due to the complex nature of the splicing machinery, splicing in vitro must currently be carried out in either cell extracts or partially purified systems (Mayas et al. 2006). Cell extracts exhibit autofluoresence due to the presence of colored species such as flavins and porphyrins (Billinton and Knight 2001). Nonetheless, we
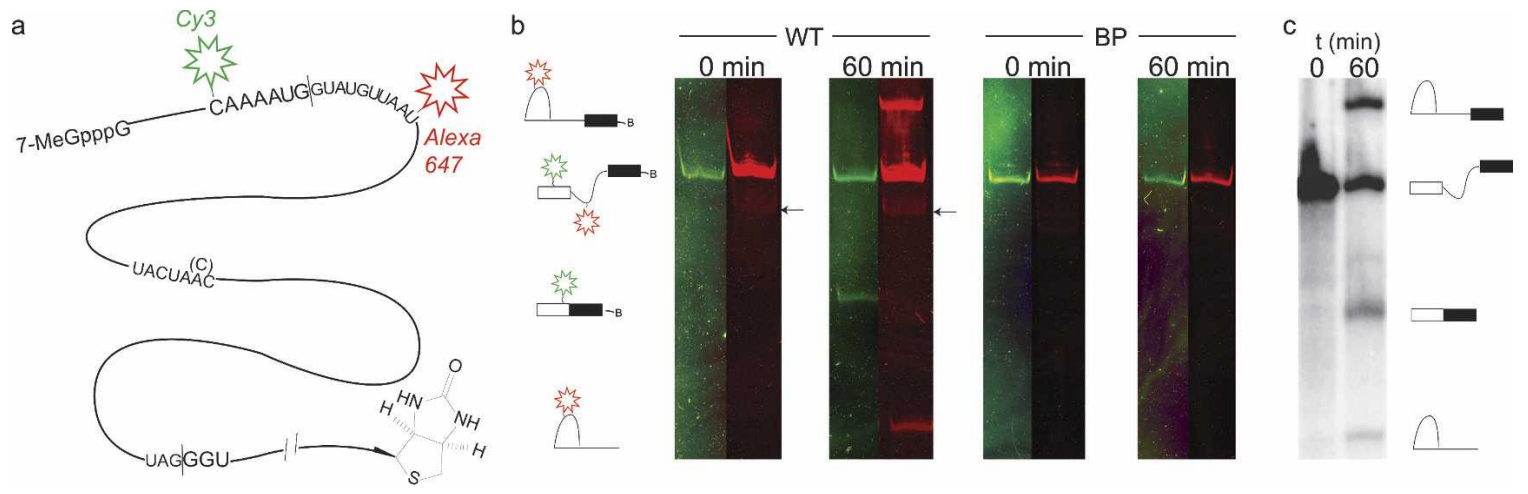

FIGURE 3. Design and bulk splicing of a covalently tagged pre-mRNA. (a) Fluorescent pre-mRNA design. Key features are: 5'-end 7-MeGpppG-cap analog, Cy3 fluorophore covalently attached to the 5'-exon, Alexa647 fluorophore covalently attached in the intron, wild-type (UACUAAC) or mutant (UACUACC) branch point sequence, and $3^{\prime}$-biotin. (|) Splice sites; (large and small letters) exon and intron sequences. (b) Splicing of the fluorescently labeled wild-type (WT) and branch point (BP) mutant pre-mRNAs at 0 and 60 min. Image pairs show Cy3 (green) and Alexa647 (red) fluorescence from the same gel lane. In the wild-type substrate, there was a contaminant RNA band ( $\leftarrow$ ) that did not change over time. (c) Splicing of unmodified, radiolabeled wild-type pre-mRNA transcript at 0 and $60 \mathrm{~min}$. 

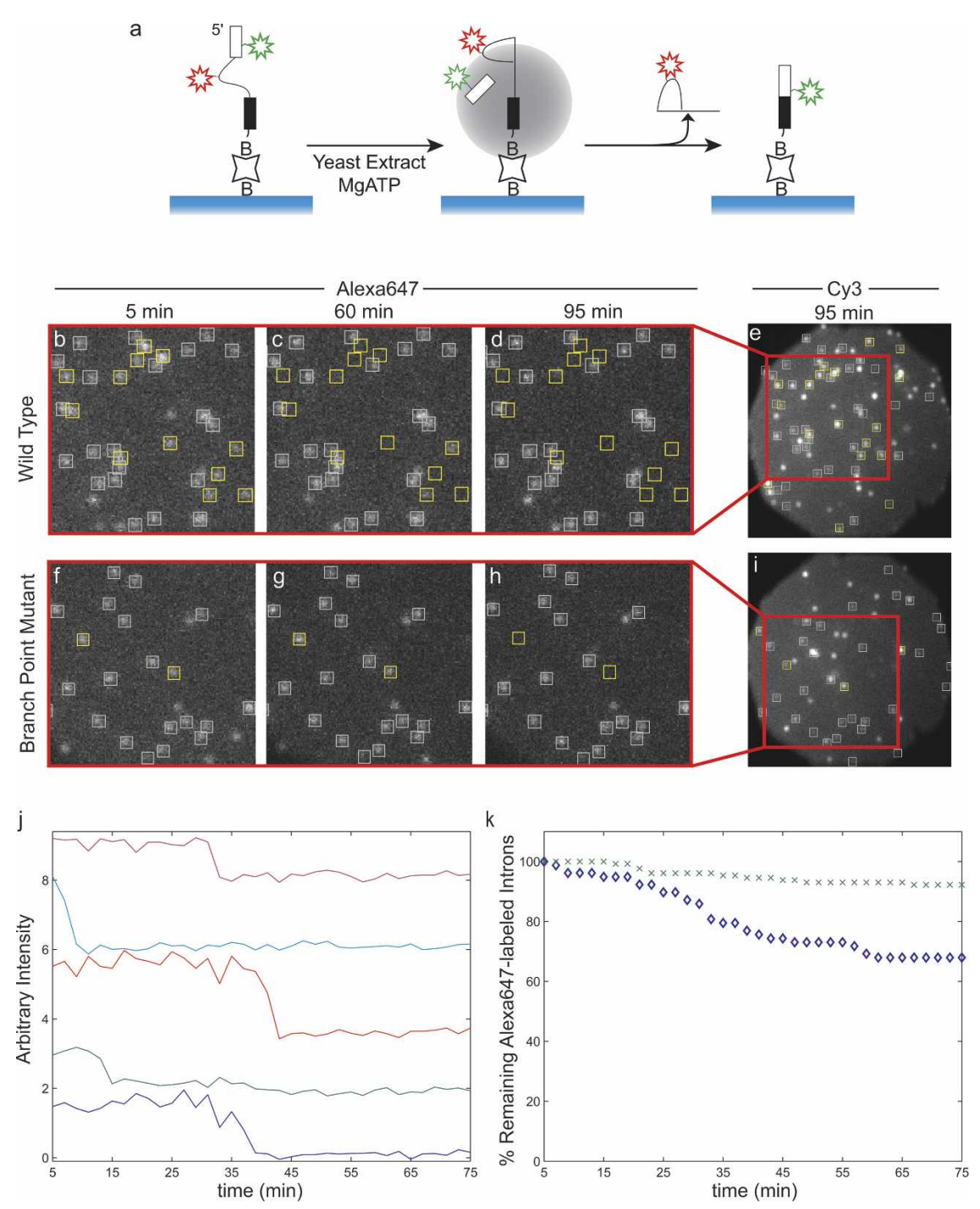

FIGURE 4. Single-molecule splicing of a covalently tagged pre-mRNA. (a) Experimental scheme. $(b-i)$ TIRF images showing the same field over time for $(b-e)$ wild-type and $(f-i)$ branch point mutant pre-mRNAs. Each molecule exhibiting both Alexa647 (intron) signal at $5 \mathrm{~min}$ and Cy3 ( $5^{\prime}$-exon) signal at $95 \mathrm{~min}$ is enclosed in a box. Some (white boxes) retain both intron and exon fluorescence throughout the experiment; others (yellow boxes) lose intron fluorescence. $(j)$ Representative single-molecule intensity time courses from wild-type pre-mRNA splicing reactions. Traces are offset on the intensity axis. $(k)$ Remaining intron fluorescence versus time of $(\diamond)$ wild-type $(N=78)$ and $(\times)$ branch point mutant $(N=129)$ molecules.

times. Indeed, of the three enzyme systems, PCD may be best suited for SMF because the enzyme is remarkably stable (Patil and Ballou 2000), does not contain a fluorescent (flavin) cofactor, and does not generate $\mathrm{H}_{2} \mathrm{O}_{2}$.

Fluorescent labeling of RNA using complementary oligos has the advantages of facile, cost-effective synthesis of the fluorescent probes and ease of retargeting fluorophores to different regions of the RNA. Although this approach has proven successful for labeling RNA for SMF experiments of short duration (tens of seconds) (Zhuang 2005; Stone et al. 2007), the much longer timeframe of pre-mRNA splicing (45-60 $\mathrm{min})$ creates a competition between intron release and oligo dissociation. While we could detect singlemolecule splicing using a $2^{\prime}$-O-Me/LNA oligo complementary to the RP51A intron, many of the observed loss of intron fluorescence events were due to oligo dissociation rather than splicing, limiting the utility of this method (Fig. 2e). It is possible, however, that other probes such as triple-helix-forming oligonucleotides (Fox and Brown 2005) or peptide nucleic acids (Robertson et al. 2006) may dissociate slowly enough to be usable.

Covalent intron labeling (Fig. 4) proved superior for detection of splicing by SMF because it eliminated the significant oligo dissociation problems inherent to the oligo-binding studies. In addition, the incorporation of a $5^{\prime}$-exon label allowed us to distinguish and ignore intron fluorescence loss due to spurious RNA cleavage. This greatly aids the interpretation of SMF experiments because it differentiates bona fide splicing from cleavage of the pre-mRNA

found that YE autofluorescence can be overcome for singlemolecule TIRF studies by utilizing brightly fluorescing dyes such as those listed in Table 1.

Fluorescent dye photostability is greatly enhanced by depleting samples of $\mathrm{O}_{2}$. However, the most widely used $\mathrm{O}_{2}$-scavenging enzyme system, glucose oxidase, is incompatible with splicing (Fig. 1). Therefore, we had to identify new means for removing $\mathrm{O}_{2}$ from our assays. We found that both galactose oxidase and protocatechuate dioxygenase (PCD) are compatible with splicing and both are as effective as glucose oxidase in extending fluorophore life- by nucleases that are unavoidably present in cell extracts. In our bulk splicing assays, up to $50 \%$ of the pre-mRNA is degraded over the course of an hour (data not shown). In the single molecule experiments, $5^{\prime}$-capping and the combination of $2^{\prime}-\mathrm{O}-\mathrm{Me}$ RNA residues and biotin attachment of the pre-mRNA at the $3^{\prime}$-end should make the RNA resistant to cleavage by exonucleases. However, endonucleolytic cleavage can still occur. By selecting only molecules that retain the $5^{\prime}$-exon label at the end of the experiment, analysis is limited to only those intron loss events attributable to either splicing or photobleaching. Comparison 
of the wild-type and branch point mutant showed that the rate of splicing was four to five times that of photobleaching. In future experiments, this ratio could be further improved by employing other dyes or by decreasing laser power and/or cumulative exposure time.

Our data demonstrate that a single-molecule approach can be used to study pre-mRNA splicing in real time within whole cell extracts. By combining multiple color TIRF microscopy with various chemical biology approaches for labeling both proteins and RNAs, this system can be adapted to answering questions about spliceosome assembly, kinetics, and disassembly that are not readily addressable using conventional bulk assays. Also, this work demonstrates that SMF can be used to directly follow biochemical processes in cell extracts. Thus, a wide range of biological systems of similar complexity to splicing should be amenable to single-molecule analysis using the methodology reported here.

\section{MATERIALS AND METHODS}

\section{Plasmids and splicing substrates}

Unmodified pre-mRNA (containing a 43-nt $5^{\prime}$-exon, 137-nt intron, and 200-nt $3^{\prime}$-exon) was transcribed from a PCR template derived from plasmid pBS117 (Seraphin and Rosbash 1991) carrying the RP51A gene (courtesy of M. Rosbash, Brandeis University). Plasmids encoding the $\mathrm{A} \rightarrow \mathrm{C}$ branch point mutant (pMJM1109) and RP51A mRNA product (no intron; pMJM1108) sequences were prepared via Quickchange mutagenesis (Makarova et al. 2000) of the pBS117 plasmid followed by complete sequencing. Capped and uniformly labeled transcripts were generated using T7 RNA polymerase, $\mathrm{m}^{7} \mathrm{G}\left(5^{\prime}\right) \mathrm{ppp}\left(5^{\prime}\right) \mathrm{G}$ cap analog (NEB), and $\left[\alpha-{ }^{32} \mathrm{P}\right] \mathrm{UTP}$ (PerkinElmer) as previously described (Moore and Query 1998). Biotinylated pre-mRNAs (WT or BP pre-mRNA-biotin) and mRNA (mRNA-biotin), and fluorescently labeled, biotinylated pre-mRNAs were prepared via RNA ligation as described later. All oligos used in these studies are listed in Table 2.

\section{Yeast extract and splicing assays}

Yeast whole-cell splicing extracts were prepared from strain BJ2168 (MATa prc1-407 prb1-1122 pep4-3 leu2 trp1 ura3-52 gal2) using the liquid $\mathrm{N}_{2}$ method and processing with either a mortar and pestle (Stevens and Abelson 2002) or ball mill (Mayas et al. 2006). Bulk splicing assays were carried out as described (Lin et al. 1985) in Splicing Buffer [100 mM KP $\mathrm{i}$ at $\mathrm{pH} 7.3,2.5 \mathrm{mM}$ $\mathrm{MgCl}_{2}, 3 \%$ PEG 8000 (w/w), 1 mM DTT], 2 mM ATP, $400 \mathrm{U} / \mathrm{mL}$ RNasin Plus Inhibitor (Promega), 30\%-40\% yeast whole cell extract, and $0.5-1 \mathrm{nM}$ pre-mRNA at room temperature. Singlemolecule and some bulk splicing assays also included $2 \mathrm{mM}$ trolox (Aldrich; added from a $200 \mathrm{mM}$ stock in DMSO, freshly prepared) (Rasnik et al. 2006) and the indicated $\mathrm{O}_{2}$-scavenging system. ATPdepleted extracts were prepared by adding $20 \mathrm{mM}$ glucose to Splicing Buffer containing 35\% YE and incubating for $5 \mathrm{~min}$ at room temperature.

\section{Fluorescent labeling of oligo 1}

Fluorescent dyes were purchased as succinimidyl esters from either Invitrogen (Alexa488, Alexa555, or Alexa647) or Amersham (Cy3). Oligo 1 was purchased with a 2'-O-bis(2-hydroxyethoxy) methyl orthoester protecting group at the $5-\mathrm{N}-\mathrm{U}$ position. This group was not removed from the oligo. Oligo 1 (40 nmol) was dissolved in $100 \mu \mathrm{L}$ of water and then extracted three times with an equal volume of chloroform before $\mathrm{EtOH}$ precipitation. Oligo $1(20 \mathrm{nmol})$ was then resuspended in water $(15 \mu \mathrm{L})$, and $70 \mu \mathrm{L}$ of $0.1 \mathrm{M} \mathrm{Na}_{2} \mathrm{~B}_{4} \mathrm{O}_{7} \mathrm{pH} 8.5$ was added. A fluorescent dye $(0.25 \mathrm{mg}$ in $15 \mu \mathrm{L}$ of DMSO) was then added to the oligo. The solution was mixed and allowed to incubate overnight in the dark at room temperature.

After labeling, oligo 1 was EtOH precipitated and resuspended in $50 \mu \mathrm{L}$ of $\mathrm{H}_{2} \mathrm{O}$ before passage through a Centrispin 10 spin column (Princeton Separations) to remove excess dye. Labeled oligo 1 was separated from the unlabeled starting material by reverse-phase HPLC (Zorbax Eclipse Plus C18; $4.6 \times 250 \mathrm{~mm}$; Agilent; 5\%-65\% $0.1 \mathrm{M}$ triethylammonium acetate to acetonitrile gradient). Fractions containing labeled oligo $\mathbf{1}$ were collected, lyophilized to dryness and resuspended in water before use. The concentration and extent of labeling were then determined by measuring the $\mathrm{UV}$-Vis absorbance of the nucleic acid and fluorophore.

\section{Fluorescent labeling of oligo 2}

Oligo 2 was labeled identically, except Alexa555 was used as the fluorophore.

\section{Fluorescent labeling of oligo 4}

Oligo 4 was purchased with 2'-O-bis(2-hydroxyethoxy)methyl orthoester protecting groups. It was deprotected by standard procedures provided by Dharmacon and subsequently EtOHprecipitated. The labeling reaction $(137 \mu \mathrm{L})$ contained $83 \mu \mathrm{g}$ of oligo 4, $9.1 \mathrm{mg} / \mathrm{mL} \mathrm{NaHCO}_{3}, 24 \% \mathrm{DMSO}$, and $1 \mathrm{mg}$ of AlexaFluor 647 carboxylic acid, succinimidyl ester (Invitrogen). The reaction was protected from light and shaken for $1 \mathrm{~h}$ at room temperature. Following EtOH precipitation, oligo 4 was trace endlabeled with $\left[\gamma^{3}{ }^{32} \mathrm{P}\right]$ ATP using polynucleotide kinase by standard methods (Sambrook and Russell 2001) and then purified on an $18 \%$ TBE-UREA PAGE gel.

\section{Ligation of Alexa647-labeled oligo 1 onto RP51A pre-mRNA or mRNA}

Alexa647-labeled oligo 1 was ligated onto the $3^{\prime}$-end of a RP51A pre-mRNA or mRNA transcript using RNA ligase (Stark et al. 2006). The transcripts contained the following sequence at its 3' -end: GAUGAAGAGAAUCCAAAAGGGUCG. Oligo 1 (56 pmol, 2 equivalents) was then $5^{\prime}$-phosphorylated in a total volume of 5 $\mu \mathrm{L}$ using T4 polynucleotide kinase ( $5 \mathrm{U}$; New England Biolabs) and $70 \mu \mathrm{M}$ ATP for $1 \mathrm{~h}$ at $37^{\circ} \mathrm{C}$ before heat inactivation for $20 \mathrm{~min}$ at $65^{\circ} \mathrm{C}$. The RP51A transcript (1 equivalent), a DNA bridge oligo (oligo 3, 1.5 equivalents), water, and $10 \times$ RNA ligase buffer (New England Biolabs) were added to oligo 1 for a final volume of $18 \mu \mathrm{L}$. The bridge and oligo were annealed to the pre-mRNA by heating for $3 \mathrm{~min}$ to $65^{\circ} \mathrm{C}$, followed by cooling for $5 \mathrm{~min}$ to $25^{\circ} \mathrm{C}$. RNasin Plus Inhibitor ( $1 \mu \mathrm{L}, 40 \mathrm{U})$ and T4 RNA Ligase ( $1 \mu \mathrm{L}, 20 \mathrm{U}$; New England Biolabs) were then added and allowed to react for $1 \mathrm{~h}$ at 
$37^{\circ} \mathrm{C}$. The final products (pre-mRNA-biotin or mRNA-biotin) were purified on a $5 \% 1 \times \mathrm{TBE}$ denaturing gel.

\section{Preparation of fluorescently labeled RP51A-biotin pre-mRNAs}

Oligo 6, representing the first $26 \mathrm{nt}$ of the capped $5^{\prime}$-exon, was prepared by first transcribing (trace $\left[\alpha-{ }^{32} \mathrm{P}\right] \mathrm{UTP}-$ labeled) fulllength RP51A pre-mRNA with T7 RNA polymerase, followed by gel purification on a $5 \% 1 \times$ TBE denaturing gel. The 26-nt fragment was then generated by RNase $\mathrm{H}$ (Invitrogen) cleavage with a chimeric 2'-O-methyl RNA/DNA oligonucleotide (oligo 7) (Inoue et al. 1987; Lapham and Crothers 1996; Stone et al. 2007) and purification on a $5 \% \times$ TBE denaturing gel. Oligo 8 , a 308-nt fragment representing most of the intron and the $3^{\prime}$-exon, was prepared by transcription of a trace $\left[\alpha-{ }^{32} \mathrm{P}\right] \mathrm{UTP}$-labeled RP51A RNA generated from a PCR template initiated $17 \mathrm{nt}$ downstream from the $5^{\prime}$-splice site, followed by gel purification and RNase $\mathrm{H}$ cleavage (with oligo 9) as above.

Oligo 1 (56 pmol, 2 equivalents) was trace Alexa488-labeled, 5' phosphorylated (trace ${ }^{32} \mathrm{P}$-labeled), and ligated onto oligo 8 using RNA ligase as above. Alexa647-labeled oligo 4 ( $5^{\prime}$-phosphorylated as above, trace ${ }^{32} \mathrm{P}$-labeled), the oligo 8-1 RNA-ligase product (7.5 pmol), and oligo 6 were ligated using a cDNA splint (oligo 5) in a 2:3:4:3 molar ratio of oligo 6: oligo 4: oligo 8-1: oligo 5 as described (Moore and Query 2000) with DNA ligase (USB) in a final volume of $96 \mu \mathrm{L}$.

\section{Oxygen scavenging}

Glucose oxidase (Aspergillus niger, Sigma Type VIIS) and catalase (bovine liver, Sigma C40) were used as previously described (Yildiz et al. 2003). Activated (green form) P. pastoris galactose oxidase (1400 U/mg, $10 \mathrm{mg} / \mathrm{mL}$ ) (Whittaker and Whittaker 2000), a generous gift from James Whittaker (Oregon Health and Sciences University), was added to a final concentration of 140 $\mathrm{U} / \mathrm{mL}$, along with $30 \mathrm{mM}$ galactose and $1500 \mathrm{U} / \mathrm{mL}$ catalase. $B$. cepacia PCD (5 U/mg, $9 \mathrm{mg} / \mathrm{mL}$ ), a generous gift of David Ballou (University of Michigan), was assayed before use (Patil and Ballou 2000) and added to a final concentration of $0.9 \mathrm{U} / \mathrm{mL}$ along with $5 \mathrm{mM}$ protocatechuate. Protocatechuate (Sigma) was recrystallized twice from hot water before use. Identical conditions were used for Pseudomonas PCD (Sigma; $4 \mathrm{U} / \mathrm{mg}$, resuspended to $6 \mathrm{mg} / \mathrm{mL}$ in $50 \mathrm{mM}$ Tris $\mathrm{pH} 8$ ). All enzymes were stored at $-80^{\circ} \mathrm{C}$.

Dactylium dendroides galactose oxidase (Sigma) was evaluated as an $\mathrm{O}_{2}$-scavenging enzyme. It inhibited the splicing reaction, and the reconstituted enzyme was mostly in the partially reduced, inactive blue form (data not shown).

\section{Assessing oligo specificity}

To analyze its binding specificity, oligo $2(20 \mathrm{nM})$ was incubated with either RP51A-biotin pre-mRNA or RP51A-biotin mRNA (40 $\mathrm{nM})$ in Splicing Buffer. After annealing $\left(5 \mathrm{~min}\right.$ at $75^{\circ} \mathrm{C} ; 15 \mathrm{~min}$ at room temperature), an aliquot was combined 5:1 with $30 \%$ glycerol, $1 \mathrm{mM}$ EDTA and loaded onto a $20 \%$ polyacrylamide, $1 \times$ TBE native gel at $4^{\circ} \mathrm{C}$. The gel was imaged using a Typhoon fluorescence/PhosphorImager (GE Healthcare) to detect Alexa555 (oligo 2) and Alexa647 (pre-mRNA and mRNA). To test the effects of oligo 2 on bulk splicing, pre-mRNA ( $7 \mathrm{nM}, 1$ equivalent) was heated and cooled as above in either buffer alone or buffer plus oligo 2 ( $35 \mathrm{nM}, 5$ equivalents). Samples were then diluted 10 -fold into a splicing reaction as above.

\section{Multiwavelength TIRF microscopy}

Splicing reaction image sequences were recorded using a multiwavelength single-molecule fluorescence microscope that has been previously described (Friedman et al. 2006). Any laser combination $(488,532$, or $633 \mathrm{~nm})$ was chosen for dye excitation, and the emission optics produced a spectrally discriminated dual view of a sample region: fluorescence emissions at wavelengths $<635 \mathrm{~nm}$ form one image, while those with wavelengths $>635 \mathrm{~nm}$ form a second image of the same sample region. The excitation laser beams transit the objective before and after a total internal reflection (TIR) from the coverslip-buffer interface, where the reflection excites sample fluorophores only within an $\sim 100-\mathrm{nm}$ distance from the coverslip surface. Employing multiple laser excitation wavelengths was enabled by directing the input and exit laser beams using small broadband mirrors in place of the dichroic mirror ordinarily found in through-the-objective fluorescence microscopes. Intensity calibration of the camera was performed as described (Friedman et al. 2006).

Focus was stabilized during long splicing reactions by periodically sensing the objective-slide distance using a 785-nm infrared laser beam (Power Technology). The 785-nm beam was introduced along the same TIR path as the three lasers used for dye excitation $(488,532$, and $633 \mathrm{~nm})$, but the infrared beam can be applied without photobleaching any of the fluorophores. After reflection from the coverslip-buffer interface, the 785-nm beam passed back through the objective and was directed onto a quadrant photodiode (Thorlabs). Any focus drift altered the exit angle of the 785-nm beam and was therefore sensed by the quadrant photodiode and automatically corrected through the piezoelectrically actuated stage that positions the sample slide.

\section{Preparation of streptavidin-coated glass slides}

Single-molecule flow chambers with a polyethylene glycol:biotinconjugated glass surface were prepared as described (Friedman et al. 2006). Immediately before use, the chambers were washed twice with $100 \mathrm{mM} \mathrm{KP}_{\mathrm{i}}$ (pH 7.3), 3\% polyethylene glycol 8000, and $2.5 \mathrm{mM} \mathrm{MgCl}_{2}$. The chamber surfaces were then blocked by washing three times with splicing buffer $+0.1 \mathrm{mg} / \mathrm{mL}$ bovine serum albumin (BSA) for $5 \mathrm{~min}$. Then $0.2 \mathrm{mg} / \mathrm{mL}$ streptavidin in splicing buffer+0.1 mg/mL BSA was bound to the slide for $30 \mathrm{~min}$, and next unbound streptavidin was washed away with $3 \times$ splicing buffer $+0.1 \mathrm{mg} / \mathrm{mL}$ BSA.

\section{Analysis of $\mathrm{O}_{2}$-scavenging systems by SMF}

Fluorescently labeled oligo $1(\sim 1 \mathrm{nM})$ was mixed with streptavidin $(8 \mu \mathrm{g} / \mathrm{mL}$; Prozyme) in Splicing Buffer plus $0.1 \mathrm{mg} / \mathrm{mL}$ BSA (Nuclease-Free; CalBioChem) and allowed to incubate for $5 \mathrm{~min}$ at room temperature. The solution was then applied to a PEGbiotin derivatized glass flow cell prepared as previously described (Friedman et al. 2006) and allowed to incubate for another $5 \mathrm{~min}$. The flow cell was then washed with $200 \mu \mathrm{L}$ of buffer containing $\mathrm{O}_{2}$ scavenger and $2 \mathrm{mM}$ Trolox. When applicable, $100 \mu \mathrm{L}$ of Splicing Buffer containing 35\% YE, $\mathrm{O}_{2}$ scavenger, and $2 \mathrm{mM}$ 
Trolox was added subsequently. Data were collected and analyzed using custom MATLAB (The Mathworks) software as previously described (Friedman et al. 2006). Survival curves were fit to $y=100 \mathrm{e}^{-k t}$, where $y$ is the percentage of surviving fluorophores at time $t$ and $k$ is the rate constant for photobleaching. The fluorophore lifetime $(\tau)$ is equivalent to $k^{-1}$.

\section{Single-molecule splicing assays}

For assays using the complementary oligo approach, oligo 2 (500 $\mathrm{nM}$ ) was annealed with wild-type or $\mathrm{A} \rightarrow \mathrm{C}$ branch point mutant RP51A-biotin pre-mRNA (100 nM; $10 \mu \mathrm{L}$ final volume) as above. The mixture was then diluted 1:50 in Splicing Buffer plus $0.1 \mathrm{mg} /$ $\mathrm{mL}$ BSA (Nuclease-Free; CalBioChem) and $8 \mu \mathrm{g} / \mathrm{mL}$ streptavidin (Prozyme), and allowed to incubate for $5 \mathrm{~min}$ at room temperature. This solution was applied to a PEG-biotin derivatized glass flow cell and allowed to incubate for an additional $5 \mathrm{~min}$. The flow cell was then washed with $200 \mu \mathrm{L}$ of buffer containing $\mathrm{O}_{2}$ scavenger and $2 \mathrm{mM}$ Trolox. Splicing reactions were initiated by addition of $100 \mu \mathrm{L}$ of Splicing Buffer containing $2 \mathrm{mM}$ ATP, 35\% yeast extract, $400 \mathrm{U} / \mathrm{mL}$ RNasin Plus, and $\mathrm{O}_{2}$ scavenger plus $2 \mathrm{mM}$ Trolox.

For assays using internally labeled RNAs, strepavidin was prebound to PEG-biotin derivatized glass flow cells as described earlier prior to application of fluorescent pre-mRNA ( $\sim 50-200$ pmol) in Splicing Buffer plus $2 \mathrm{mM}$ ATP, 1:100 RNasin plus (Promega), $2 \mathrm{mM}$ Trolox, and $\mathrm{O}_{2}$ scavenger. Once sufficient premRNA binding had been confirmed using the TIRF microscope, unbound molecules were removed by washing and splicing was initiated as above.

Data were collected and analyzed using GLIMPSE (http:// www.brandeis.edu/projects/gelleslab/glimpse/glimpse.html) and custom MATLAB (The Mathworks) software as previously described (Friedman et al. 2006). To limit photobleaching during splicing reactions, a single frame ( $1 \mathrm{sec}$ exposure) was acquired intermittently such that cumulative photobleaching was $\leq 10 \%$.

\section{ACKNOWLEDGMENTS}

We thank M. Rosbash, D. Ballou, and J. Whitaker for the generous gifts of plasmids and enzymes as noted in the text. This work was supported in part by NIH grants GM53007 (M.J.M.), GM043369 and GM081648 (J.G.), and GM00714 (L.J.F). M.J.M. is an HHMI Investigator, A.A.H. is a NIH NRSA Postdoctoral Fellow, grant GM079971, and D.J.C. was supported by NIH training grant GM759628.

Received August 24, 2007; accepted October 11, 2007.

\section{REFERENCES}

Benesch, R.E. and Benesch, R. 1953. Enzymatic removal of oxygen for polarography and related methods. Science 118: 447-448.

Billinton, N. and Knight, A.W. 2001. Seeing the wood through the trees: A review of techniques for distinguishing green fluorescent protein from endogenous autofluorescence. Anal. Biochem. 291: 175-197.

Brenner, T.J. and Guthrie, C. 2006. Assembly of Snu114 into U5 snRNP requires Prp8 and a functional GTPase domain. RNA 12: 862-871.

Burge, C.B., Tuschl, T., and Sharp, P.A. 1999. Splicing of precursors to mRNAs by the spliceosomes. In The RNA world (eds. R.F.
Gesteland et al.), pp. 525-560. Cold Spring Harbor Laboratory Press, Cold Spring Harbor, NY.

Cornish, P.V. and Ha, T. 2007. A survey of single-molecule techniques in chemical biology. ACS Chem. Biol. 2: 53-61.

Fox, K.R. and Brown, T. 2005. An extra dimension in nucleic acid sequence recognition. Q. Rev. Biophys. 38: 311-320.

Friedman, L.J., Chung, J., and Gelles, J. 2006. Viewing dynamic assembly of molecular complexes by multiwavelength singlemolecule fluorescence. Biophys. J. 91: 1023-1031.

Ha, T. 2001. Single-molecule fluorescence resonance energy transfer. Methods 25: 78-86.

Inoue, H., Hayase, Y., Iwai, S., and Ohtsuka, E. 1987. Sequence-dependent hydrolysis of RNA using modified oligonucleotide splints and RNase H. Nucleic Acids Symp. Ser. 1987: 221224.

Jurica, M.S. and Moore, M.J. 2003. Pre-mRNA splicing: Awash in a sea of proteins. Mol. Cell 12: 5-14.

Kelley, A.M., Michalet, X., and Weiss, S. 2001. Chemical physics. Single-molecule spectroscopy comes of age. Science 292: 16711672.

Lapham, J. and Crothers, D.M. 1996. RNase H cleavage for processing of in vitro transcribed RNA for NMR studies and RNA ligation. RNA 2: 289-296.

Liao, X.C., Colot, H.V., Wang, Y., and Rosbash, M. 1992. Requirements for U2 snRNP addition to yeast pre-mRNA. Nucleic Acids Res. 20: 4237-4245. doi: 10.1093/nar/20.16.4237.

Lin, R.J., Newman, A.J., Cheng, S.C., and Abelson, J. 1985. Yeast mRNA splicing in vitro. J. Biol. Chem. 260: 1478014792.

Makarova, O., Kamberov, E., and Margolis, B. 2000. Generation of deletion and point mutations with one primer in a single cloning step. Biotechniques 29: 970-972.

Mayas, R.M., Maita, H., and Staley, J.P. 2006. Exon ligation is proofread by the DExD/H-box ATPase Prp22p. Nat. Struct. Mol. Biol. 13: 482-490.

Moore, M.J. and Query, C.C. 1998. Use of site-specifically modified RNAs constructed by RNA ligation. In RNA: Protein interactions-A practical approach (ed. C.W.J. Smith), pp. 75-108. Oxford University Press, New York.

Moore, M.J. and Query, C.C. 2000. Joining of RNAs by splinted ligation. Methods Enzymol. 317: 109-123.

Newman, A.J., Lin, R.J., Cheng, S.C., and Abelson, J. 1985. Molecular consequences of specific intron mutations on yeast mRNA splicing in vivo and in vitro. Cell 42: 335-344.

Nilsen, T.W. 2003. The spliceosome: The most complex macromolecular machine in the cell? Bioessays 25: 1147-1149.

Ohi, M.D., Ren, L., Wall, J.S., Gould, K.L., and Walz, T. 2007. Structural characterization of the fission yeast U5 $\bullet$ U2/U6 spliceosome complex. Proc. Natl. Acad. Sci. 104: 3195-3200.

Patil, P.V. and Ballou, D.P. 2000. The use of protocatechuate dioxygenase for maintaining anaerobic conditions in biochemical experiments. Anal. Biochem. 286: 187-192.

Rasnik, I., Myong, S., Cheng, W., Lohman, T.M., and Ha, T. 2004. DNA-binding orientation and domain conformation of the E. coli rep helicase monomer bound to a partial duplex junction: Singlemolecule studies of fluorescently labeled enzymes. J. Mol. Biol. 336: 395-408.

Rasnik, I., McKinney, S.A., and Ha, T. 2006. Nonblinking and longlasting single-molecule fluorescence imaging. Nat. Methods 3: 891-893.

Robertson, K.L., Yu, L., Armitage, B.A., Lopez, A.J., and Peteanu, L.A. 2006. Fluorescent PNA probes as hybridization labels for biological RNA. Biochemistry 45: 6066-6074.

Ruby, S.W. and Abelson, J. 1988. An early hierarchic role of U1 small nuclear ribonucleoprotein in spliceosome assembly. Science 242: $1028-1035$.

Rymond, B.C. and Rosbash, M. 1985. Cleavage of 5' splice site and lariat formation are independent of $3^{\prime}$ splice site in yeast mRNA splicing. Nature 317: 735-737. 
Sambrook, J. and Russell, D.W. 2001. Molecular cloning: A laboratory manual, 3rd ed. Cold Spring Harbor Laboratory Press, Cold Spring Harbor, NY.

Seraphin, B. and Rosbash, M. 1991. The yeast branchpoint sequence is not required for the formation of a stable U1 snRNA-pre-mRNA complex and is recognized in the absence of U2 snRNA. EMBO J. 10: 1209-1216.

Small, E.C., Leggett, S.R., Winans, A.A., and Staley, J.P. 2006. The EFG-like GTPase Snu114p regulates spliceosome dynamics mediated by Brr2p, a DExD/H box ATPase. Mol. Cell 23: 389-399.

Staley, J.P. and Guthrie, C. 1998. Mechanical devices of the spliceosome: Motors, clocks, springs, and things. Cell 92: 315-326.

Stark, H. and Luhrmann, R. 2006. Cryoelectron microscopy of spliceosomal components. Annu. Rev. Biophys. Biomol. Struct. 35: 435-457.

Stark, M.R., Pleiss, J.A., Deras, M., Scaringe, S.A., and Rader, S.D. 2006. An RNA ligase-mediated method for the efficient creation of large, synthetic RNAs. RNA 12: 2014-2019.
Stevens, S.W. and Abelson, J. 2002. Yeast pre-mRNA splicing: Methods, mechanisms, and machinery. Methods Enzymol. 351: 200-220.

Stone, M.D., Mihalusova, M., O'Connor, C.M., Prathapam, R., Collins, K., and Zhuang, X. 2007. Stepwise protein-mediated RNA folding directs assembly of telomerase ribonucleoprotein. Nature 446: 458-461.

Tatei, K., Kimura, K., and Ohshima, Y. 1989. New methods to investigate ATP requirement for pre-mRNA splicing: Inhibition by hexokinase/glucose or an ATP-binding site blocker. J. Biochem. 106: $372-375$.

Whittaker, J.W. 2002. Galactose oxidase. Adv. Protein Chem. 60: 1-49. Whittaker, M.M. and Whittaker, J.W. 2000. Expression of recombinant galactose oxidase by Pichia pastoris. Protein Expr. Purif. 20: 105-111.

Yildiz, A., Forkey, J.N., McKinney, S.A., Ha, T., Goldman, Y.E., and Selvin, P.R. 2003. Myosin V walks hand-over-hand: Single fluorophore imaging with 1.5-nm localization. Science 300: 2061-2065.

Zhuang, X. 2005. Single-molecule RNA science. Annu. Rev. Biophys. Biomol. Struct. 34: 399-414. 

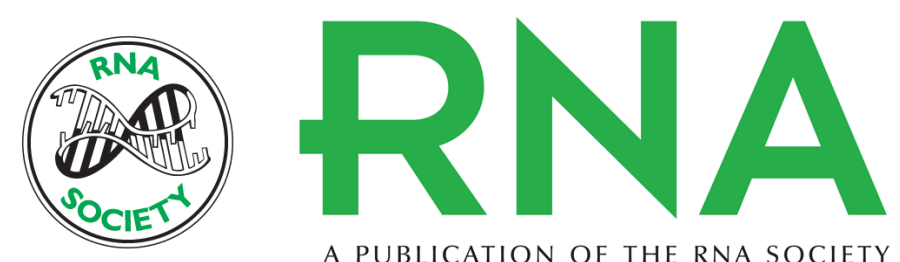

A PUBLICATION OF THE RNA SOCIETY

\section{Visualizing the splicing of single pre-mRNA molecules in whole cell extract}

Daniel J. Crawford, Aaron A. Hoskins, Larry J. Friedman, et al.

RNA 2008 14: 170-179

References This article cites 37 articles, 9 of which can be accessed free at: http://rnajournal.cshlp.org/content/14/1/170.full.html\#ref-list-1

\section{License}

Email Alerting Receive free email alerts when new articles cite this article - sign up in the box at the Service top right corner of the article or click here.

To subscribe to $R N A$ go to:

http://rnajournal.cshlp.org/subscriptions 